\title{
O ensino de História Indígena: possibilidades, exigências e desafios com base na Lei 11.645/2008
}

The Teaching of Indigenous History: possibilities, demands and challenges from the 11.645/2008 Law

Edson Silva*

\section{Resumo}

Com suas mobilizações, os povos indígenas conquistaram nas últimas décadas considerável visibilidade como atores sociopolíticos, o que vem exigindo discussões sobre a implantação de políticas públicas que respondam às suas demandas por direitos sociais específicos. A Lei 11.645/2008, que determinou a inclusão do ensino de História e das Culturas indígenas nos currículos escolares, pretende possibilitar o respeito dos demais brasileiros em relação aos povos indígenas e o reconhecimento das sociodiversidades no país.

Palavras-chave: povos indígenas; sociodiversidade; ensino de História.

\begin{abstract}
With their mobilizations, indigenous peoples have gained considerable visibility in recent decades as sociopolitical players, which has demanded discussions on the implementation of public policies that meet demands for their specific social rights. Law 11645/2008, which led to the inclusion of Indigenous Cultures and History in school curricula, aims to facilitate the respect of other Brazilians in relation to indigenous peoples and the recognition of social diversity in the country.

Keywords: Indigenous people; social diversity; History teaching.
\end{abstract}

Como lecionar sobre os povos indígenas, se é fácil constatar que a imensa maioria do professorado na Educação Básica desconhece a população indígena em nosso país e nem sabe quantos brasileiros se autodeclararam índios no censo IBGE/2010? Como tratar dos povos indígenas, se no senso comum e no ambiente escolar apenas se conhecem os índios da Região Norte e do Xingu? Esses são considerados portadores de uma suposta 'cultura pura', em oposição aos indígenas de outras regiões que sofreram colonização há mais tempo - o Nor-

\footnotetext{
${ }^{*}$ Centro de Educação, Universidade Federal de Pernambuco. Av. Acadêmico Helio Ramos, s/n, Cidade Universitária. 50740-520 Recife - PE - Brasil. edson.edsilva14@yahoo.com.br
} 
deste, por exemplo -, os quais têm suas identidades sistematicamente negadas e são chamados de 'caboclos'. Essa expressão foi muito utilizada sobretudo a partir de meados do século XIX pelos invasores das terras indígenas e pelas autoridades, todos defendendo o fim dos aldeamentos e invisibilizando, assim, esses povos na história.

Como superar a visão comumente exótica sobre os povos indígenas em sala de aula, para substituí-la por uma abordagem crítica? Essas e outras questões permeadas de desinformações, equívocos, ignorância generalizada e, portanto, preconceitos contra 'os índios' são grandes desafios para o ensino da história indígena e para as reflexões sobre esse tema.

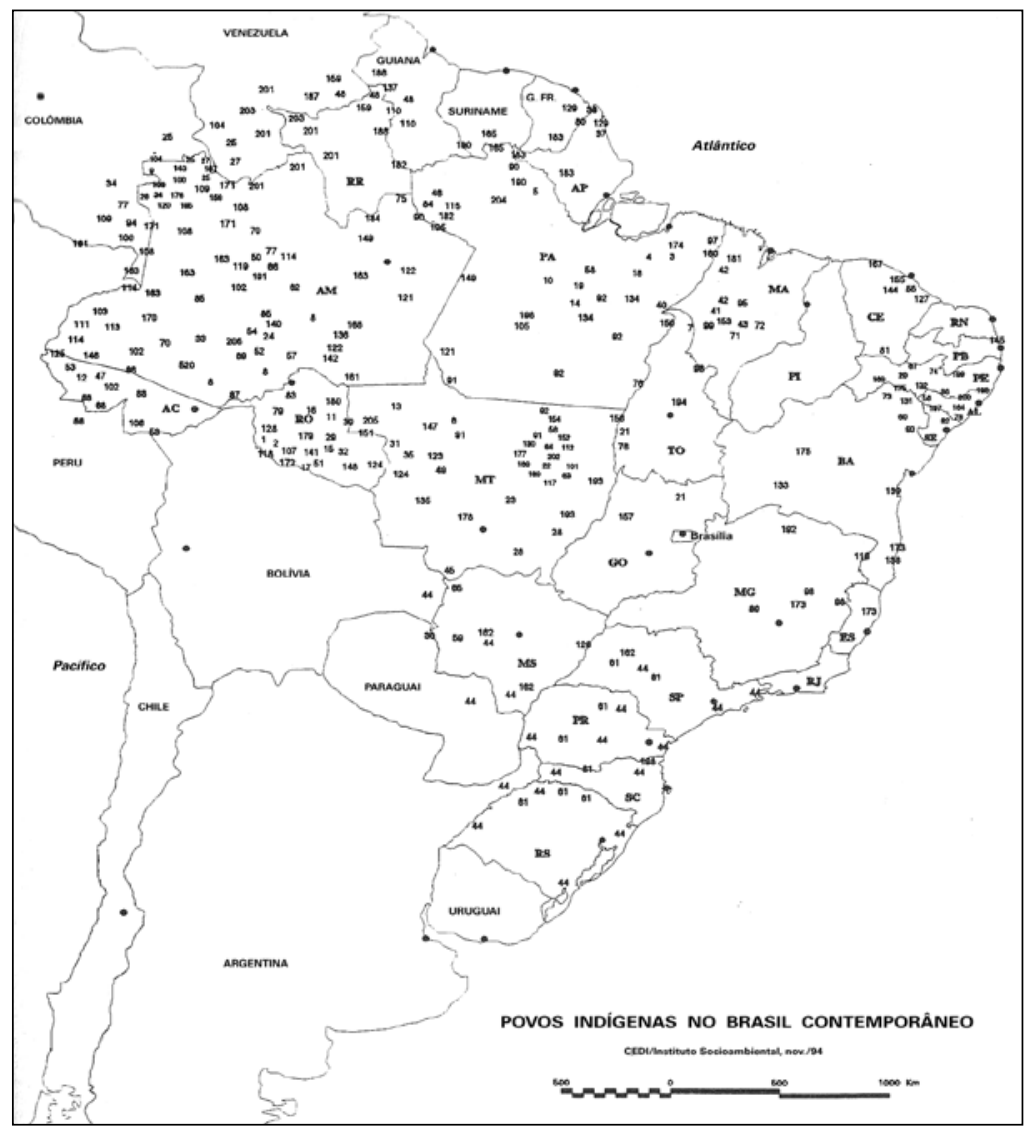

Figura 1 - A falta de um mapa atualizado com as populações indígenas no Brasil expressa o quanto a temática indígena ainda espera por investimentos em estudos. ${ }^{1}$ 


\section{RECONHECENDO A SOCIODIVERSIDADE INDÍGENA}

Onde estão os índios? A imensa maioria da população brasileira - até mesmo pessoas mais esclarecidas - responde que não sabe. O pouco conhecimento está associado basicamente à imagem do indígena tradicionalmente veiculada pela mídia: um 'índio genérico', com biótipo formado por características correspondentes aos indivíduos de povos habitantes da Região Amazônica e do Xingu: cabelos lisos, pinturas corporais e abundantes adereços de penas, nus, moradores das florestas, de culturas exóticas, falantes de uma língua estranha.

Também são chamados de 'tribos' na perspectiva etnocêntrica e evolucionista de uma suposta hierarquia de raças pela qual os índios ocupariam obviamente o último degrau. São ainda imortalizados pela literatura romântica produzida no século XIX, como nos livros de José de Alencar, onde são apresentados índios belos e ingênuos, ou valentes guerreiros e ameaçadores canibais. Ou seja, bárbaros, bons selvagens ou heróis.

Mas essas visões sobre os indígenas vêm mudando nos últimos anos, em razão da visibilidade política conquistada por eles. As mobilizações dos povos indígenas em torno dos debates para a elaboração da Constituição de 1988 e as conquistas dos direitos indígenas fixados na lei maior do país possibilitaram a garantia dos direitos (demarcação das terras, saúde e educação diferenciadas e específicas etc.), para que a sociedade em geral (re)descobrisse os indígenas.

Observemos que o mapa do Brasil (Figura 1) aponta a presença de povos indígenas em todas as regiões do país, com maior concentração na Região Amazônica, onde a fronteira capitalista ainda é recente. Os impactos da colonização europeia, por sua vez, são constatados no pequeno número de grupos indígenas ao longo do litoral brasileiro. Ampliando-se o mapa veremos também maior concentração na região do Sertão, entre Alagoas, Bahia e Pernambuco, mais especificamente nas proximidades do rio São Francisco, região disputadíssima até a atualidade entre os índios e os colonizadores de ontem e de hoje.

Vejamos o que diz o índio Gersem Baniwa - lembrando que o povo Baniwa habita a fronteira entre Brasil, Colômbia e Venezuela, em aldeias às margens do rio Içana e de seus afluentes, além de comunidades no Alto Rio Negro e nos centros urbanos de São Gabriel da Cachoeira, Santa Isabel e Barcelos 
(AM). Mestre e Doutor em Antropologia pela UnB, Gersem publicou o livro $O$ índio brasileiro: o que você precisa saber sobre os povos indígenas no Brasil de hoje, onde escreveu sobre a sociodiversidade dos povos indígenas:

A sua diversidade, a história de cada um e o contexto em que vivem criam dificuldades para enquadrá-los em uma definição única. Eles mesmos, em geral, não aceitam as tentativas exteriores de retratá-los e defendem como um princípio fundamental o direito de se autodefinirem. ${ }^{2}$

Após discorrer sobre as complexidades das organizações sociopolíticas dos diferentes povos indígenas nas Américas questionando as visões etnocêntricas dos colonizadores europeus, o pesquisador indígena afirma:

Desta constatação histórica importa destacar que, quando falamos de diversidade cultural indígena, estamos falando de diversidade de civilizações autônomas e de culturas; de sistemas políticos, jurídicos, econômicos, enfim, de organizações sociais, econômicas e políticas construídas ao longo de milhares de anos, do mesmo modo que outras civilizações dos demais continentes europeu, asiático, africano e a Oceania. Não se trata, portanto, de civilizações ou culturas superiores ou inferiores, mas de civilizações e culturas equivalentes, mas diferentes. (Baniwa, 2006, p.49)

Figura 2 - Exemplos da sociodiversidade indígena no Brasil. ${ }^{3}$
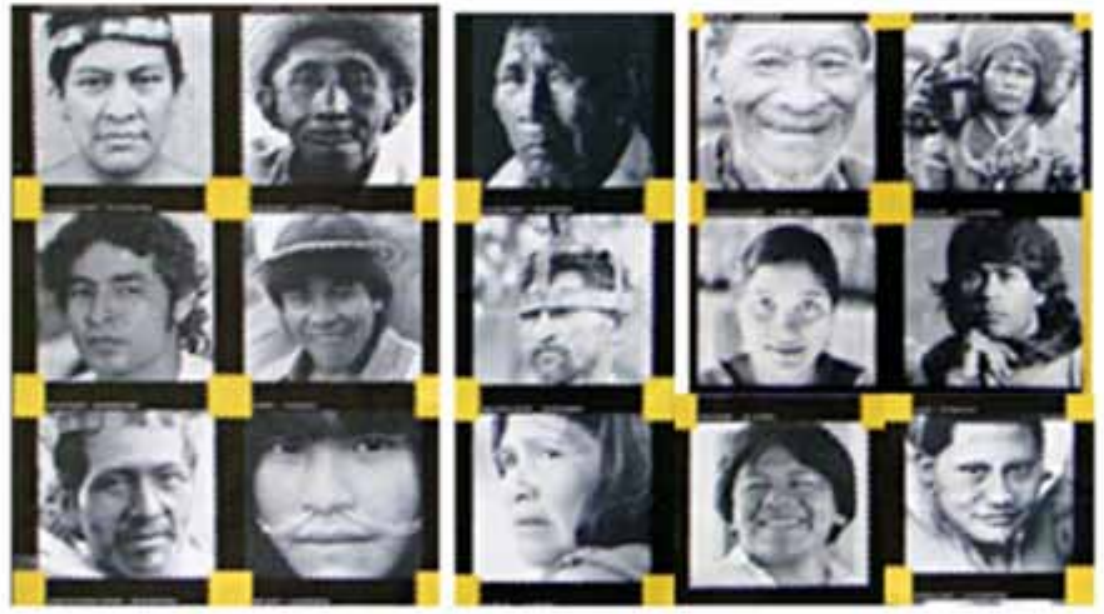
Tratando da chamada identidade cultural brasileira, Gersem conclui que

não existe uma identidade cultural única brasileira, mas diversas identidades que, embora não formem um conjunto monolítico e exclusivo, coexistem e convivem de forma harmoniosa, facultando e enriquecendo as várias maneiras possíveis de indianidade, brasilidade e humanidade. Ora, identidade implica a alteridade, assim como a alteridade pressupõe diversidade de identidades, pois é na interação com o outro não idêntico que a identidade se constitui. O reconhecimento das diferenças individuais e coletivas é condição de cidadania quando identidades diversas são reconhecidas como direitos civis e políticos, consequentemente absorvidos pelos sistemas políticos e jurídicos no âmbito do Estado Nacional. (Baniwa, 2006, p.49)

Afirmar a sociodiversidade indígena no Brasil é, portanto, reconhecer os direitos às diferenças socioculturais. É buscar compreender as possibilidades de coexistência sociocultural, fundamentada nos princípios da interculturalidade, pois

A interculturalidade é uma prática de vida que pressupõe a possibilidade de convivência e coexistência entre culturas e identidades. Sua base é o diálogo entre diferentes, que se faz presente por meio de diversas linguagens e expressões culturais, visando à superação de intolerância e da violência entre indivíduos e grupos sociais culturalmente distintos. (Baniwa, 2005, p.51)

Em anos recentes os indígenas vêm conquistando o (re)conhecimento e o respeito a seus direitos específicos e diferenciados. Sob essa ótica o país, a sociedade brasileira se repensa, se vê em sua multiplicidade, pluralidade e diversidade sociocultural, expressa também pelos povos indígenas em diferentes contextos sócio-históricos. Mas lembremos que esse reconhecimento exige também novas posturas e medidas das autoridades governamentais em ouvir dos diferentes sujeitos sociais a demanda por novas políticas públicas que reconheçam, respeitem e garantam essas diferenças.

Na Educação, por exemplo, pretende-se a formulação de políticas inclusivas das histórias e expressões socioculturais no currículo escolar, nas práticas pedagógicas. ${ }^{4}$ Essa exigência deve ser atendida com a contribuição de especialistas, a participação dos próprios sujeitos sociais, os índios, na formação de futuros/as docentes, na formação continuada daqueles que discutem a temática 
indígena e atuam na produção de subsídios didáticos em todos os níveis de ensino, seja nas universidades ou nas secretarias estaduais e municipais. Só assim deixaremos de tratar as diferenças socioculturais como estranhas, exóticas e folclóricas. (Re)conhecendo em definitivo os 'índios' como povos indígenas, com seus direitos de expressões próprias que podem contribuir decisivamente para a nossa sociedade, para todos nós, para a riqueza da humanidade.

Se as mobilizações trouxeram nas últimas décadas considerável visibilidade para os povos indígenas como atores sociopolíticos em nosso país, exigindo novos olhares, pesquisas e reflexões, ${ }^{5}$ é preciso contestar o desconhecimento, os preconceitos, os equívocos e a desinformação generalizada sobre os indígenas, até mesmo entre os educadores. Várias expressões populares - como 'programa de índio', usada para referir situações desconfortáveis - ilustram muito bem como os preconceitos contra os indígenas são afirmados cotidianamente. E o mais grave: esse tipo de atitude independe do lugar social e político ocupado por quem expressa tais preconceitos.

\section{RECONHECENDO A SOCIODIVERSIDADE, REPENSANDO O BRASIL}

Quais as razões da busca pelo reconhecimento legal de direitos específicos e diferenciados na atualidade? Por que atualmente são obrigatórias rampas em prédios públicos, destinadas às pessoas portadoras de necessidades especiais? Por que existem delegacias para as mulheres? Por que existe o Estatuto do Idoso? O que levou à criação do Estatuto da Criança e do Adolescente (ECA)? Por que se aprovou a Lei 11.645/2008, que tornou obrigatório nos currículos escolares o ensino da História e Culturas Afro-brasileiras e Indígenas?

As respostas a essas e outras perguntas semelhantes podem ser encontradas nas observações à organização sociopolítica do Brasil contemporâneo. Nas últimas décadas, em novos cenários políticos, os movimentos sociais com diferentes atores conquistaram e ocuparam seus espaços, reivindicando o reconhecimento e o respeito às sociodiversidades. Identidades foram afirmadas, diferentes expressões socioculturais passaram a ser reconhecidas e respeitadas, mudanças de atitudes que exigiram discussões, formulações e fiscalizações de políticas públicas que respondam às demandas por direitos sociais específicos e diferenciados. 
A nossa sociedade, como resultado da organização e mobilização dos movimentos sociais, se descobre plural, repensa seu desenho: o Brasil não tem uma identidade nacional única! Somos um país de muitos rostos, expressões socioculturais, étnicas, religiosas etc. As minorias (maiorias) - sejam mulheres, ciganos, negros, idosos, crianças, portadoras de necessidades especiais etc. reivindicam o reconhecimento e o respeito aos seus direitos.

Faz-se necessário, então, descontruir a ideia de uma suposta identidade genérica nacional, regional. Questionar as afirmações que expressam uma cultura hegemônica que nega, ignora e mascara as diferenças socioculturais. Uma suposta identidade e uma cultura nacional que se constituem pelo discurso impositivo de um único povo. Uma unidade anunciada muitas vezes em torno da ideia de raça, um tipo biológico a exemplo das imagens sobre o mulato, o mestiço, o gaúcho, o paulista, o mineiro, o nordestino e o sertanejo, entre outras.

As ideias de uma identidade e uma cultura nacional escondem as diferenças de classes sociais, de gênero e étnicas, ao buscar uniformizá-las. Negam também os processos históricos marcados pelas violências de grupos politicamente hegemônicos, negando ainda as violências sobre grupos, a exemplo dos povos indígenas e dos oriundos da África que foram submetidos a viverem em ambientes coloniais. Observemos ainda que as identidades nacionais, além de serem fortemente marcadas pelo etnocentrismo, o são também pelo sexismo: dizemos 'o mulato', 'o mestiço', 'o paulista', 'o gaúcho', 'o mineiro', 'o carioca', 'o baiano', 'o cearense', 'o pernambucano' etc., acentuando o gênero masculino.

É necessário, ainda mais, problematizar as ideias e afirmações de identidades gerais como a mestiçagem no Brasil - um discurso bastante utilizado para negar, desprezar e suprimir as sociodiversidades existentes no país. Reconhecer, afirmar e respeitar o direito às diferenças é, pois, questionar o discurso da mestiçagem como identidade nacional, usado para esconder a história de índios e negros na História do Brasil.

\section{A LEI 11.645/2008: POSSIBILIDADES, EXIGÊNCIAS E DESAFIOS PARA O (RE)CONHECIMENTO DA SOCIODIVERSIDADE INDÍGENA}

No âmbito da escola/educação formal, em seus vários níveis, pode-se constatar muita ignorância que resulta em distorções a respeito dos indígenas. A Lei 11.645 de março de 2008, que tornou obrigatório o ensino de história e 
culturas indígenas nos currículos escolares no Brasil, ainda que careça de definições mais completas, possibilita a superação dessa lacuna na formação escolar. Contribui para o reconhecimento e a inclusão das diferenças étnicas dos povos indígenas, buscando pensar um novo desenho do Brasil em sua sociodiversidade.

Passados mais de 4 anos de sua publicação, persistem vários desafios para efetivação do que determinou a Lei 11.645/2008. É de fundamental importância, por exemplo, capacitar os quadros técnicos de instâncias governamentais (federais, estaduais e municipais) para o combate aos racismos institucionais. Mas um grande desafio - ou o maior deles - é a capacitação de professores. Tanto dos que estão atuando (a chamada 'formação continuada') quanto daqueles ainda em formação nas universidades públicas e privadas, nos diversos cursos de licenciatura e magistério. Isso significa dizer que no âmbito dos currículos dos cursos de licenciatura e de formação de professores deve ocorrer a inclusão de cadeiras obrigatórias, ministradas por especialistas, tratando especificamente da temática indígena. Sobretudo em cursos das áreas das Ciências Humanas e Sociais.

É preciso que as secretarias estaduais e municipais incluam ainda a temática indígena nos estudos, nas capacitações periódicas e na formação continuada, e a abordagem deve se dar na perspectiva da sociodiversidade historicamente existente no Brasil: por meio de cursos, seminários, encontros de estudos específicos e interdisciplinares destinados ao professorado e aos demais trabalhadores/as em educação, com a participação de indígenas e a assessoria de especialistas reconhecidos. É preciso, também, adquirir livros que tratem da temática indígena, destinados ao acervo das bibliotecas escolares.

Outro grande desafio e urgente necessidade é a produção - com assessorias de pesquisadores e especialistas - de vídeos, subsídios didáticos, textos etc. sobre os povos indígenas, para utilização em sala de aula, proporcionando ainda o acesso a publicações - livros, revistas, jornais e fontes de informações e pesquisas sobre os povos indígenas.

A efetivação da Lei 11.645 possibilitará estudar, conhecer e compreender a temática indígena. Superar desinformações, equívocos e a ignorância que resultam em estereótipos e preconceitos sobre os povos indígenas, reconhecendo, respeitando e apoiando os povos indígenas nas reivindicações, conquistas e garantias de seus direitos e em suas diversas expressões socioculturais. 
A efetivação dessa Lei, além de mudar antigas práticas pedagógicas preconceituosas, favorecerá novos olhares para a História e a Sociedade. Na nossa sociedade a escola tem papel privilegiado na formação humana, buscando responder às demandas sociais. Ainda que se levem em conta as dificuldades e os desafios presentes nos processos de ensino-aprendizagem, no fazer pedagógico, a escola é um lócus onde a efetivação da Lei possibilitará viabilizar “espaços que favoreçam o reconhecimento da diversidade e uma convivência respeitosa baseada no diálogo entre os diferentes atores sociopolíticos, oportunizando igualmente o acesso e a socialização dos múltiplos saberes" ${ }^{6}$ Assim, contribuirá para a formação de cidadãos críticos, possibilitando o reconhecimento das diferenças socioculturais existentes no Brasil, o reconhecimento dos direitos da sociodiversidade dos povos indígenas.

\section{Sugestões bibliográficAS E DE CONTEÚdos} PARA O ESTUDO DA TEMÁTICA INDÍGENA

O ponto de partida para o ensino crítico da temática indígena consiste em considerar sempre a atualidade dos povos indígenas. Ou seja, por meio de usos de mapas para localização dos povos indígenas atuais, desvincular a ideia de passado colonial em que todos os índios supostamente foram exterminados. O Censo do IBGE/2010 contabilizou a população indígena no Brasil em cerca de 900 mil indivíduos - os que se autodeclararam índios.

Um segundo ponto é a ênfase nas sociodiversidades indígenas, desmistificando imagens genéricas do 'índio', da chamada 'cultura indígena'. É preciso discutir as diferentes expressões socioculturais indígenas no passado e no presente, questionando a clássica dicotomia 'Tupi' versus 'Tapuia'. Sugere-se, por exemplo, utilizar fotografias para demonstrar as sociodiversidades dos povos indígenas no Brasil.

Um terceiro aspecto a ser estudado consiste em evidenciar a participação efetiva dos povos indígenas nos diversos momentos históricos ao longo da História do Brasil, desnaturalizando a ideia equivocada da presença do 'índio' apenas na época do 'Descobrimento' ou somente na 'formação do Brasil'. Ou seja, problematizando o lugar pensado e o ocupado pelos povos indígenas na história do país. 
É preciso promover momentos de intercâmbio entre os povos indígenas e os estudantes durante o calendário letivo, por meio de visitas previamente preparadas do alunado às aldeias, bem como de indígenas às escolas. Essa ação deve ser desenvolvida sobretudo nos municípios onde atualmente habitam povos indígenas, como forma de buscar a superação dos preconceitos e as discriminações. Vale ressaltar que as visitas não devem se constituir como meras apresentações folclóricas, mas como espaços de diálogos e aprendizagens.

Finalmente, é preciso discutir e propor o apoio aos povos indígenas por meio do estímulo ao alunado para a realização de abaixo-assinados, cartas às autoridades com denúncias e exigência de providências diante de violências, assassinatos de lideranças indígenas etc. Estimularemos, assim, por meio de manifestações coletivas na sala de aula, o apoio às campanhas de demarcação das terras e à garantia dos direitos dos povos indígenas.

\section{Indicações bibliográficas sobre a temática indígena}

CUNHA, Manuela Carneiro da (Org.). História dos índios no Brasil. São Paulo: Companhia das Letras, 1992.

FAUSTO, Carlos. Os índios antes do Brasil. Rio de Janeiro: Zahar, 2000.

FERREIRA, Maria Kawall Leal (Org.). Ideias matemáticas de povos culturalmente distintos. São Paulo: Global, 2002.KUPER, Adam. Cultura, a visão dos antropólogos. Bauru (SP): Edusc, 2002.

LARAIA, Roque de Barros. Cultura: um conceito antropológico. Rio de Janeiro: Zahar, 1986.

LIMA, Antonio Carlos de Souza. Um grande cerco de paz: poder tutelar, indianidade e formação do Estado no Brasil. Petrópolis (RJ): Vozes, 1995.

MACEDO, Ana Vera L. S.; NUNES, Ângela; SILVA, Aracy Lopes da (Org.). Crianças indígenas: ensaios antropológicos. Rio de Janeiro: Global, 2002.

MELATTI, Júlio César. Índios do Brasil. São Paulo: Edusp, 2008.

MONTEIRO, John M. Negros da terra: índios e bandeirantes nas origens de São Paulo. São Paulo: Companhia das Letras, 1994.

OLIVEIRA, João Pacheco de (Org.). A presença indígena no Nordeste: processos de territorialização, modos de reconhecimento e regimes de memória. Rio de Janeiro: Contra Capa, 2011.

OLIVEIRA, João Pacheco de (Org.). A viagem de volta: etnicidade, política e reelaboração cultural no Nordeste indígena. 2.ed. Rio de Janeiro: Contra Capa, 2004. 
POMPA, Cristina. Religião como tradução. São Paulo: Edusc, 2003.

RICARDO, Carlos Alberto; RICARDO, Fany (Org.). Povos indígenas no Brasil: 2006/2010. São Paulo: Instituto Socioambiental - ISA, 2011.

SILVA, Aracy Lopes da; FERREIRA, Mariana Kawal Leal (Org.). Antropologia, História e Educação: a questão indígena e a escola. São Paulo: Global, 2001.

\section{Indicações de sites:}

Índio Educa: www.indioeduca.org

Tema indígena: temaindigena.blogspot.com

Índios on line: www.indiosonline.net

Índios no Nordeste: www.indiosnonordeste.com.br

Instituto Socioambiental: www.isa.org.br

Conselho Indigenista Missionário - Cimi: www.cimi.org.br

Os índios na História do Brasil: www.ifch.unicamp.br/ihb

\section{NOTAS}

${ }^{1}$ GRUPIONI, Luís Donizete Benzi; SILVA, Aracy Lopes da. (Org.). A temática indígena na escola. 4.ed. São Paulo: Global, 2011. p.56.

${ }^{2}$ BANIWA, Gersem dos Santos Luciano. O índio brasileiro: o que você precisa saber sobre os povos indígenas no Brasil de hoje. Brasília: MEC/Secad; Rio de Janeiro: Museu Nacional/UFRJ, 2006. p.47.

${ }^{3}$ Adaptado de ISA - Instituto Socioambiental. Povos indígenas no Brasil: 1987-1990. São Paulo, 1989.

${ }^{4}$ GOMES, Nilma L. A questão racial na escola: desafios colocados pela implementação da Lei 10.639/2003. In: MOREIRA, Antonio F; CANDAU, Vera M. Multiculturalismo: diferenças culturais e práticas pedagógicas. 2.ed. Petrópolis (RJ): Vozes, 2008. p.67-89.

${ }^{5}$ ALMEIDA, Maria R. C. Os índios na história do Brasil. Rio de Janeiro: Ed. FGV, 2010.

${ }^{6}$ SILVA, Maria da Penha da. A temática indígena no currículo escolar à luz da Lei 11.645/2008. Cadernos de pesquisa, São Luís, UFMA, v.17, n.2, p.39-47, maio-ago. 2010.

Artigo recebido em 15 de julho de 2012. Aprovado em 12 de setembro de 2012. 